Kansas State University Libraries

New Prairie Press

\title{
DEVELOPMENT OF WILD OAT SEED DISPERSAL DISTRIBUTIONS USING AN INDIVIDUAL-PLANT GROWTH SIMULATION MODEL
}

William J. Price

Bahman Shafii

Donald C. Thill

Follow this and additional works at: https://newprairiepress.org/agstatconference

Part of the Agriculture Commons, and the Applied Statistics Commons

\section{(c) (1) $\Theta(9$}

This work is licensed under a Creative Commons Attribution-Noncommercial-No Derivative Works 4.0 License.

\section{Recommended Citation}

Price, William J.; Shafii, Bahman; and Thill, Donald C. (2000). "DEVELOPMENT OF WILD OAT SEED DISPERSAL DISTRIBUTIONS USING AN INDIVIDUAL-PLANT GROWTH SIMULATION MODEL," Conference on Applied Statistics in Agriculture. https://doi.org/10.4148/2475-7772.1246

This is brought to you for free and open access by the Conferences at New Prairie Press. It has been accepted for inclusion in Conference on Applied Statistics in Agriculture by an authorized administrator of New Prairie Press. For more information, please contact cads@k-state.edu. 


\title{
DEVELOPMENT OF WILD OAT SEED DISPERSAL DISTRIBUTIONS USING AN INDIVIDUAL-PLANT GROWTH SIMULATION MODEL
}

\author{
William J. Price, Bahman Shafii \\ Statistical Programs \\ Donald C. Thill \\ Division of Plant Science \\ College of Agriculture \\ University of Idaho \\ Moscow, Idaho
}

\begin{abstract}
An individual-plant growth simulation model for quantifying competition between spring barley and wild oat has been previously described (Price, Shafii, and Thill, 1994). Individual plants within a population were modeled independently and competition between plants was determined by resource demand within plant specific areas-of-influence. Calibration of the model to spring barley and wild oat biomass data was performed and shown to have a high degree of accuracy under monoculture conditions. The work presented here applies the specified model to a larger scale simulation for the purpose of demonstrating seed dispersal in wild oat. This is accomplished by breaking the annual cycle of wild oat seeds into the three integrated phases: Growth and development, dissemination, and dormancy. The growth and development phase is handled using the individual-plant growth model. The subsequent dispersal of seeds is described using two-dimensional stochastic processes. Finally, a life table analysis, based on predetermined transition probabilities, is used to establish the makeup of populations in the following season. A sensitivity analysis which examines various biological, ecological, and mechanical components over a 10 year period is carried out and the potential use in weed science education is demonstrated.
\end{abstract}

KEYWORDS: Individual-based modeling, Plant competition, Seed dissemination, Simulation algorithm

\section{INTRODUCTION}

Computer modeling of plant competition is often carried out using a stand-level approach. These models use input variables based on field averages taken over entire populations or plant stands. They are commonly used to describe agronomic problems such as weed-crop interactions (see for example, Cousens, et al., 1987) or crop production (see for example, Wilkerson, 1990). Although stand-level models are computationally simple and may be good for predictive purposes, they fail to account for heterogeneity within plant populations as well as any small scale spatial 
variability. In contrast, individual-based models provide an alternative form of simulation where the basic modeling unit is reduced to an individual plant. These models allow for heterogeneous populations with spatial variability, and thus, are more flexible as exploratory tools. They have been applied to agriculture settings (for example, Aikman and Watkinson, 1980) as well as a wide range of ecological problems including systems in forestry and rangeland (DeAngelis and Gross, 1992). However, given their detailed nature, individual-based models are often limited as a generalized predictive device and may be computationally difficult to implement.

Price, et al. (1994) have developed an individual-based plant growth model for simulating plant competition between wild oat and spring barley. The model used specified areas-ofinfluence unique to each plant in combination with limited plant resources as the underlying mechanisms for competition. It was controlled by two governing principles relating to resource demand within the plant AOI and growth following resource acquisition. Calibration and validation was successfully carried out for each species, although model performance was found to be best in monoculture scenarios. In particular, the model accurately reproduced the biomassdensity relationships observed in experimental data on each species.

Individual-based plant growth models present a convenient platform upon which larger simulations can be based. For example, the wild oat model mentioned above can be expanded to incorporate seed dissemination in an agronomic system over several generations. Factors influencing seed spread, such as dispersal mechanisms, agronomic practices, or plant life histories, can be explored while the individual-based model inherently accounts for plant competition. The expanded model would have great potential as a teaching tool where students and instructors could easily make observations and comparisons on various agronomic variables that are not feasible or possible to evaluate in the classroom.

The objective of this paper is to demonstrate seed dissemination based on the individualplant growth model for wild oat. Examples will be given which explore factors influencing the mechanical, biological and ecological aspects of wild oat seed dispersal in a spring barley cropping system.

\section{METHODS}

\section{Individual-plant growth model}

The individual-plant growth model for wild oat and spring barley is based on a circular Area-of-Influence (AOI) for each plant (Price et al. 1994). Each AOI is located on a grid of 1 $\mathrm{cm}^{2}$ cells representing the field. Each grid cell contains a fixed amount of plant resources that are accessible to the plant through a resource demand function:

$$
D_{j}=\exp \left(-\alpha_{i} * D I S T\right)
$$

where $D_{j}$ is the relative resource demand at the $\mathrm{j}^{\text {th }}$ cell of the AOI, $\alpha_{i}$ is a parameter measuring the degree of resource demand of the $\mathrm{i}^{\text {th }}$ plant, and DIST is the distance of the $\mathrm{j}^{\text {th }}$ cell from the AOI center. This function results in diminishing resource demand as distance from the plant center increases. The total resource requirements of the plant are then determined by summing (1) over 
all grid cells in the AOI. This resource evaluation phase occurs once for every plant in each of 50 equally spaced time periods. The resources acquired over time are used to determine plant growth (increase in the plant AOI) according to the cumulative logistic function:

$$
R_{i(t+1)}=\frac{R_{M A X i}}{\left(1+\exp \left(B * U_{i(t)}\right)\right)}
$$

where $R_{i((t+))}$ is the new $\mathrm{AOI}$ radius at time period $\mathrm{t}, R_{M A X i}$ is the maximum attainable radius of the $\mathrm{i}^{\text {th }}$ plant grown with no competition, $B$ is a growth rate parameter, and $U_{i(t)}$ is the cumulative level of resources realized for the $i^{\text {th }}$ plant at time $t$. This sigmoidal function is typical of plant growth over time. It exhibits slow initial growth, followed by a rapid increase in size that subsequently slows to asymptotically approach the plant's maximum possible radius, $R_{M A X i}$.

A flow chart outlining the iterative algorithm of the model is given in Figure 1. During each time period, plants were assessed independently and in random order. They extracted resources from the field on a first come-first serve basis and, thus, individuals assessed later in the time period were potentially deprived of adequate resources. This resource driven interaction among plants created the competitive mechanism within the model. The competitiveness of individuals was determined by the parameters $\alpha_{i}$ and $R_{M A X i}$. Together these can be taken as a measure of aggressivity where smaller values of $\alpha_{i}$ and larger values of $R_{M A X i}$ lead to higher levels of competition. When competition occurs, it limits $U_{i(t)}$ and slows plant growth in (2), thereby reducing the final size of the plant AOI. The AOI size is an important measure of a plant's performance because the model computes plant biomass as a quantity proportional to its radius.

For each species, the biomass data were used for model calibration. This was achieved by comparing the biomass-density relationships of observed experimental data to those generated by the model. The specific relationship used was the inverse yield function given by Spitters (1983):

$$
y=\frac{1}{(a+b * N)}
$$

where $y$ is the biomass per plant, $a$ is the inverse of a plant's biomass grown without competition, $\mathrm{b}$ is a coefficient of intraspecific competition, and $\mathrm{N}$ is the plant density. This function describes a response which decreases asymptotically towards zero as plant density increases. To start the calibration process, a least squares fit of (3) was made to the observed data. Simulated biomass data were subsequently generated from simulations that incrementally set the model parameters $\alpha_{i}$ and $R_{M A X i}$ to values within a specified range. Least squares fits of (3) were also made to this data. The final calibrated values for $\alpha_{i}$ and $R_{M A X i}$ were chosen such that they minimized the distance between the least squares fit of the observed data and that of the model (Price, 1999).

Model validation was carried out by combining the calibrated wild oat and spring barley models into a mixed species simulation. As with the calibration procedure, model generated data was compared to observed data. In this case, the comparison utilized a yield function similar to (3), but modified to include multiple plant species and interspecific competition (Cousens, et al., 1987). 


\section{Seed Dispersal Simulation}

The seed dispersal simulation was divided into three sequential steps corresponding to seasonal periods. The first of these was a spring component where plant growth and development were managed using the individual-plant growth model described above. Fall, the second phase, provided for both natural and mechanical seed dispersal mechanisms. The final stage, winter, carried out a life table analysis on the wild oat population incorporating a weed seed bank. The details for each of these components will be addressed below.

\section{Spring Component}

In the spring component, the productivity of each plant was based on the individual plant growth model described above. Using experimental data from Evans (1987), a linear relationship describing seed production as a function of plant biomass was developed. This relationship was incorporated into the individual-plant model so that model output reflected seed production. The seed output of each individual was subsequently made available for dispersal by the fall component.

\section{Fall Component}

The dispersal algorithm or fall component determined the spatial layout of the plant populations. Wild oat seed dispersal was considered to have three possible outcomes. Seeds could be naturally dispersed, falling in the immediate vicinity of the mother plant. Alternatively, they could be picked up by the combine harvester and mechanically spread. Lastly, they could be removed from the field by the combine harvester. Movement of seeds by other methods was not considered.

Natural seed dispersal, in this case, implies seeds falling from the plant. The distance and direction of seed rain relative to the source can be described as a stochastic process. Candidate models for seed rain might include common forms such as the Gaussian, exponential, Cauchy or uniform probability distributions. Earlier work in this area has indicated that the tails of the distribution are important in determining the final seed fall pattern (Shaw, 1995). Distributions with "lighter" tails, e.g. Gaussian or exponential, will produce a wave front or spherical spatial pattern of population growth, while a "heavier" tailed distribution, such as the Cauchy, will result in an infestation with surrounding satellite colonies. For wild oat, the later scenario exhibiting satellite colony formation was deemed more appropriate. Thus, the Cauchy distribution was adopted for natural dispersal. The maximum distance a seed could fall from the mother plant was limited to $2 \mathrm{~m}$. The direction of falling seeds was considered to be unbiased and was, therefore, based on the uniform distribution ranging from 0 to $360^{\circ}$. The resulting pattern of seed fall was concentrated around the plant with occasional seeds falling further away. The percentage of the new seed population subjected to natural dispersal each year was set prior to the simulation.

The mechanical component of dispersal considered factors influencing both the distance and direction that seeds could be thrown from the back of a harvester. As with natural seed fall, the distance a seed travels from the harvester can be described stochastically. While no experimental data was available to measure this phenomena, field observations indicated that most seeds fall immediately after exiting the combine, while a few seeds are thrown further. This 
suggested that a distribution like the Cauchy might again be appropriate for modeling distance. For the seed direction, a Beta $(1,1)$ distribution adjusted to $-60^{\circ}$ to $+60^{\circ}$ from the swath centerline was adopted. While this setting produced a uniform distribution in that range, the Beta distribution was a convenient functional form to use because a simple reparameterization would have allowed the incorporation of some directional bias into the harvester model. Such a modification could duplicate asymmetrical seed spread due to equipment, wind, etc. The combination of both the distance and directional elements resulted in seed distributions which were symmetrical over the combine swath (Figure 2). Douglas, et al. (1989) have reported similar results for chaff distributions in cereal production. A third component of the mechanical dispersal algorithm was added that allowed seeds to be carried down field. When the combine picks up plant material, it takes time to process and separate the material before depositing the chaff. During that processing time, the combine continues to move down field, thus skewing any weed seed populations in the direction of travel. For this simulation, this factor was set randomly between 5 and $10 \mathrm{~m}$ for each seed. The percentage of seeds mechanically dispersed in each year of the simulation was fixed at the beginning of the run.

Any seeds remaining after natural and mechanical dispersals were accounted for, were considered to have been removed from the field by the combine. The degree to which this can occur depends on the settings of the natural and mechanical dispersal models given above and reflects how effective the combine harvester is at removing weed seeds.

\section{Winter Component}

After seed dispersal, the fate of each seed was decided in the simulation's winter phase. The winter component was essentially one of bookkeeping implemented through a life table analysis. For a species such as wild oat, the life history includes seed dormancy. That is, at each annual stage of the simulation, seeds either germinated or entered a quiescent phase of no activity. In the life table analysis, transition between states of germination and dormancy were controlled using transition probabilities. These were either set on an annual basis or fixed across all iterations. Figure 3 gives an outline of three iterations. The seeds present in each year (rows) are divided into a germinated class $(\mathrm{Gm})$, and 5 dormant classes $\left(\mathrm{Dm}_{1}-\mathrm{Dm}_{5}\right)$. Seeds that germinate in the first year produce offspring that may germinate the following year with probability $g_{1}$ or become dormant with probability $\mathrm{d}_{1}$. They could also produce seeds that are subject to predation or otherwise considered nonviable and, therefore, are removed from the simulation with probability $p_{1}$. Likewise, seeds in the $i^{\text {th }}$ dormant class in each year, $\mathrm{Dm}_{\mathfrak{i}}$, could germinate, remain dormant or die with the respective probabilities $g_{i}, d_{i}$, and $p_{i}$. This type of analysis was carried out for every seed and, hence, determined the population structure for each annual iteration.

\section{Additional Component}

To further enhance the flexibility of the simulation, a fourth component was constructed to allow the introduction of extraneous variables such as environmental variability, management strategies, etc. This was accomplished using a graphical concept known as "masking" and involved overlaying the plant grid with a spatially corresponding image. Color intensities on the masking image represented the values or levels of the extraneous factor. Examples of such factors might include resources, herbicide doses, management strategies, etc. Masks may be 
created for each annual cycle or applied to all simulation stages. Here, a herbicide mask is used to simulate control of wild oat in specified years.

All computations and graphics were carried out using custom C programs or SAS (1991). Program codes and results are available from the authors at http:// www.uidaho.edu/ag/statprog/kansas 00.

\section{RESULTS AND DEMONSTRATION}

\section{Individual-plant growth model}

Model behavior was shown to be consistent with biological expectations. Biomass per plant decreased and biomass per unit area increased as plant density increased. The model was accurate relative to the observed data under monoculture situations. This was mainly due to the similar resource use of all plants under such conditions. Calibration resulted in parameter estimates of $\alpha_{i}=0.01$ and $R_{M A X i}=40$ for spring barley and $\alpha_{i}=0.04$ and $R_{M A X i}=40$ for wild oat. This indicates that, while both species have equivalent levels of competitive behavior in terms of $R_{M A X i}$, spring barley is the more aggressive species because of its lower value of $\alpha_{i}$. Its shallower resource demand curve will withdraw more resources from the environment than wild oat, making it more likely that spring barley plants will achieve full growth (Price,1999).

Validation results showed some deviation from the observed data. The competitiveness of wild oat with spring barley was less than anticipated. Conversely, spring barley tended to over compete against wild oat. Nevertheless, it was still possible to implement mixed species simulations. When the density the first species was held constant and the density of the second was allowed to vary, the situation was essentially reduced to that of a monoculture scenario. This provided a basis for the wild oat seed dispersal simulation under the condition of a constant crop density. For a more detailed explanation of the complete results of the individual-plant growth model see Price, et al. (1994).

\section{Seed Dispersal Simulation}

While the individual-plant growth model was developed on a $2 \times 2 \mathrm{~m}$ grid, the seed dispersal model was expanded to cover a 50 × 50 m area, encompassing 25 million grid cells. Ten annual seasons of continuous spring barley production were simulated with an initial wild oat population $(\mathrm{Gm})$ of 500 individuals. Dormant seed classes $\mathrm{Dm}_{1}-\mathrm{Dm}_{5}$ were initialized to zero for each simulation. The transition probabilities of the life table component ranged from 0.30 to 0.75 and were based on values similar to those found by Miller and Nalewaja (1990). In general, the longer seeds remained dormant, the more likely they were to die or germinate. For each simulation, individual plant growth parameters, $\alpha_{i}$ and $R_{M A X i}$ were set to the calibrated values of $\alpha_{i}$ $=0.04$ and $R_{M A X i}=40$. The natural and mechanical seed dispersal rates were $10 \%$ and $20 \%$, respectively. These are similar to values reported by Maxwell and Ghersa (1992). All other conditions of the simulations were kept identical across the scenarios.

The area of seed dispersal presents many possibilities for investigation. This demonstration will concentrate on three scenarios based on changes imposed on ecological, managerial and biological factors. The first scenario investigated the growth of wild oat populations with two possible points of infestation: a field edge introduction and a contaminated 
crop seed introduction. The second scenario used a spray mask to assess the effects of intermediate wild oat control in years 5 through 8 . The final simulation scenario considered the longevity of the weed seed bank through the termination of seed production following year 4 . More information regarding these scenarios and their respective results can be found in Price (1999).

\section{Point of infestation}

As part of the model output, a graphical representation of the field at each annual cycle was made. This consisted of a field map that displayed varying shades of color to indicate changes in plant densities. In addition to the map, population profile plots were also given for the top-to-bottom and left-to-right field perspectives. Only the maps for the number of plants in the edge infestation scenario are demonstrated here (Figure 4). In year 1, the initial infestation can be seen as a $1 \times 5 \mathrm{~m}$ strip of seed in the lower left quadrant of the field. The profile plots indicate that the weed population rapidly drifted down field while simultaneously progressing into the field. On the field map, a banding pattern developed that coincided with the passes of the combine. These patterns were created because the combine component concentrated seed into dense swaths as well as moving seed across the field. Such patterns are not unusual and can be found in many real field conditions. Consequently, by the end of the simulation, the small initial infestation had covered approximately $50 \%$ of the field and was continuing to spread.

The second type of output was numeric and recorded the number of seeds available in each life history stage. Using the plant number data $(\mathrm{Gm})$, Figure 5 shows the changes in population size over time for the edge and contaminated seed scenarios. The edge infestation population steadily increased over time. In contrast, the contaminated seed scenario showed a very rapid increase in population size for years 2 through 4 . This subsequently stabilized to a value around 170,000. The differences seen here are mainly due to competitive factors. Although both simulations started with the same number of seeds, the contaminated scenario began with more space between plants. This allowed individuals to grow to their full capacity and produce the maximum possible number of seeds. The resulting population rapidly expanded. In year 4 , however, the density became large enough to limit resources and, hence, the population size approached a plateau. On the other hand, the edge infestation began with a more compact spatial layout and, therefore, individual growth was restricted. This restriction was continually present throughout the ten year simulation. The consequence was a slower increase in population size suggesting that infestation from contaminated crop seed was a more severe problem than smaller edge or strip infestations. The differences shown here clearly demonstrate the importance of plant competition and are, in this case, the direct result of the underlying individual-plant growth model.

\section{Herbicide Mask}

Each simulation was initialized using the contaminated seed scenario explained earlier. Thus, the results of the control scenario (no herbicide) are unchanged from those just presented. For the herbicide counterpart, the only change was the addition of $98 \%$ wild oat control in years 5 through 8. As might be expected, the herbicide treatment decreased the number of plants in those 
years (Figure 6). During each of the treated years, plant numbers progressively declined towards zero. Once control was lifted, however, the wild oat population rebounded and quickly approached the same population level as the control treatment. This rapid recovery can be explained by two factors. First, the seed bank provided a large base of recruitment to keep the population from dying out. Second, once control was lifted, the remaining plants were at low plant densities. As a result, a situation similar to the contaminated seed scenario developed allowing for rapid population growth. This demonstrates both the importance of the weed seed bank and the effects of competition in weed management. Additionally, the idea that management of weed populations requires constant monitoring is further reinforced.

\section{Seed Bank}

The last set of simulations investigated the effects of a weed seed bank. Using the starting values of the edge infestation, seed production was interrupted starting in year 4. At that point, population regeneration became solely dependent on individuals in the seed bank. Plant numbers declined asymptotically after year 4 (Figure 7). By year 10 the population had disappeared completely. The extinction of the population was only an artifact, however. Since five dormant seed classes were initially defined, it naturally took five to six annual cycles to deplete the seed bank. Had the simulation been arranged with more dormant classes, the time to extinction would have increased proportionally. Longer times in reality are not unusual, as longevities of up to 18 years have been reported in the literature (Gonzales-Andujar and Perry, 1995). Nevertheless, before extinction occurs, seeds are still present in the population long after seed production has ceased. As seen earlier, this is sufficient for populations to regain large numbers of individuals in a short period of time. The presence of dormant seeds and multiple dormant classes provides weed populations with a large regenerating potential.

\section{CONCLUDING REMARKS}

Past attempts to model plant competition have been primarily dependent on using an entire population as a single modeling unit. This technique ignores any variability which may exist within the population, as well as, any spatial variability within the environment. Individual-plant based growth models can inherently address these issues. As an example, an individual-plant model was presented which employed the resource demand of individuals to develop intra- and interspecific competitive effects. This model produced expected biological trends across varying plant densities. Specifically, it accurately reproduced the biomass-density relationships found in monoculture experimental data collected on spring barley and wild oat. Model validation on mixed species data, however, was not as successful.

Seed dispersal of wild oat in a spring barley cropping system was selected to demonstrate the capabilities of the individual-plant model. In order to circumvent the multiple species limitation, it was necessary to create a monoculture condition in a two species system. This was accomplished by holding the density of spring barley constant while allowing the density of wild oat to vary. Additional components were required for natural and mechanical seed dispersal mechanisms as well as the wild oat seed bank. Various ecological, managerial, and biological 
factors of the model were explored in the simulations. In each case, the simulation provided useful insights into weed management in spring barley. These results have great potential for weed science education and research. In classroom settings, simulations can be designed such that students and instructors can easily change specified model parameters for quick visualization and assessment.

Although the results shown here are encouraging, further work is needed to take full advantage of the individual-based model. The effects of heterogeneous populations and spatial variability on the simulation require further investigation. In addition, true multiple species simulations will require better definitions of competition and interaction between species. Nevertheless, the current model offers a useful tool for conveying important concepts in weed science education.

\section{ACKNOWLEDGEMENTS}

We appreciate the comments made by the referees on an earlier version of this manuscript. This work is published with the approval of the Idaho Agricultural Experiment Station as paper number 00-02.

\section{REFERENCES}

Aikman, D. P. and A. R. Watkinson. 1980. A model for growth and self thinning in even aged monocultures of plants. Ann. Bot. 45: 419-427.

Cousens R., S. R. Moss, G. W. Cussans, and B. J. Wilson. 1987. Modeling weed populations in cereals. Rev. Weed Sci. Weed Sci. Soc. Am. 3: 93-112.

DeAngelis, D. L. and L. J. Gross. 1992. Individual-Based Models and Approaches in Ecology. Chapman and Hall, NY. $525 \mathrm{pp}$.

Douglas, C. L., P. E. Rasmussen, and R. R. Allmaras. 1989. Cutting height, yield, level, and equipment modification effects on residue distribution by combines. Transactions of the ASAE, 32:1258-1262.

Evans, R. M. 1987. Effects of Wild Oat (Avena fatua) and Spring Barley (Hordeum vulgare) Density on Relative Aggressiveness and Spring Barley Grain Yield. Masters Thesis, University of Idaho. $24 \mathrm{pp}$.

Gonzalez-Andujar, J. L. and J. N. Perry. 1995. Models for the herbicidal control of the seed bank of Avena sterilis: the effects of spatial and temporal heterogeneity and of dispersal. Journal of Applied Ecology, 32: 578-587.

Maxwell, B. D. and C. Ghersa. 1992. The influence of weed seed dispersion versus the effect of competition on crop yield. Weed Technology, 6: 196-204.

Miller, S. D. and J. D. Nalewaja. 1990. Influence of burial depth on wild oats (Avena Fatua) seed longevity. Weed Technology, 4:514-517.

Price, W. J., B. Shafii, and D. C. Thill. 1994. An individual-plant growth simulation model for quantifying plant competition. In G. A. Milliken and J. R. Schwenke (Eds.) Proceedings of the 1994 Kansas State University Conference on Applied Statistics in Agriculture, pp. 
1-18 Kansas State University, Manhattan, Kansas.

Price, W. J. 1999. An Individual-Plant Growth Algorithm for Modeling Competition Between Spring Barley and Wild Oat with Application to Seed Dissemination. Unpublished Ph.D. Dissertation, University of Idaho, $115 \mathrm{pp}$.

SAS Institute Inc. 1991. SAS/STAT User's Guide, Version 6, Fourth Edition, Vol. 2. SAS Institute Inc, Cary, NC.

Shaw, M. W. 1995. Simulation of population expansion and spatial pattern when individual dispersal distributions do not decline exponentially with distance. Proceedings of the Royal Society of London, 259: 243-248.

Spitters, C. J. T., 1983. An alternative approach to the analysis of mixed cropping experiments. 1. Estimation of comeptition effects. Neth. J. Ag. Sci. 31: 1-11.

Wilkerson, G. G., J. W. Jones, H. D. Coble, and J. L. Gunsolos. 1990. SOYWEED: A simulation model of soybean and common cocklebur growth and competition. Agron. J. 82: $1003-1010$. 


\section{Synopsis of Program Flow}

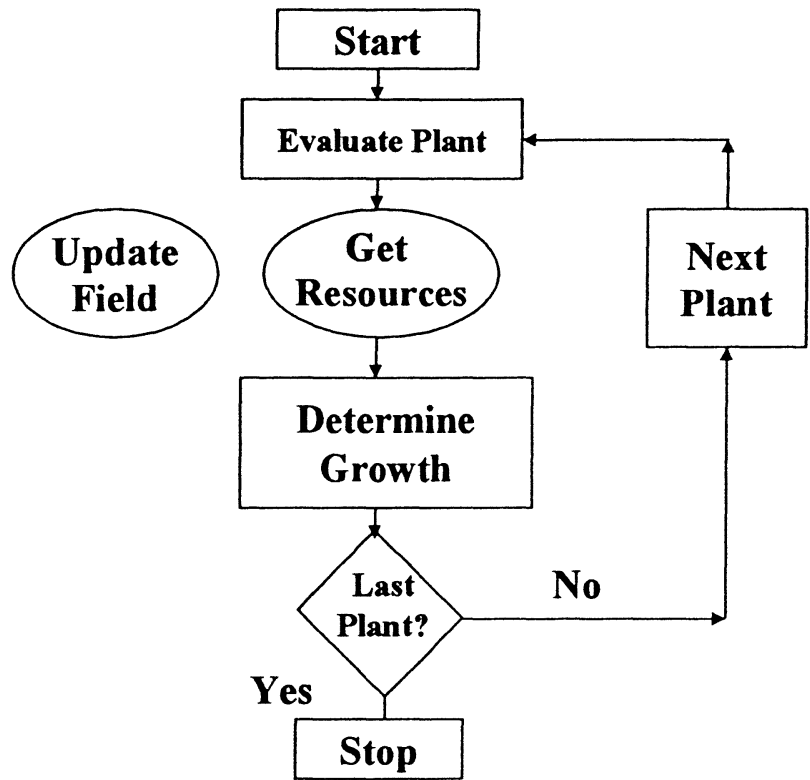

Figure 1. Flow chart for the individual-plant growth model.

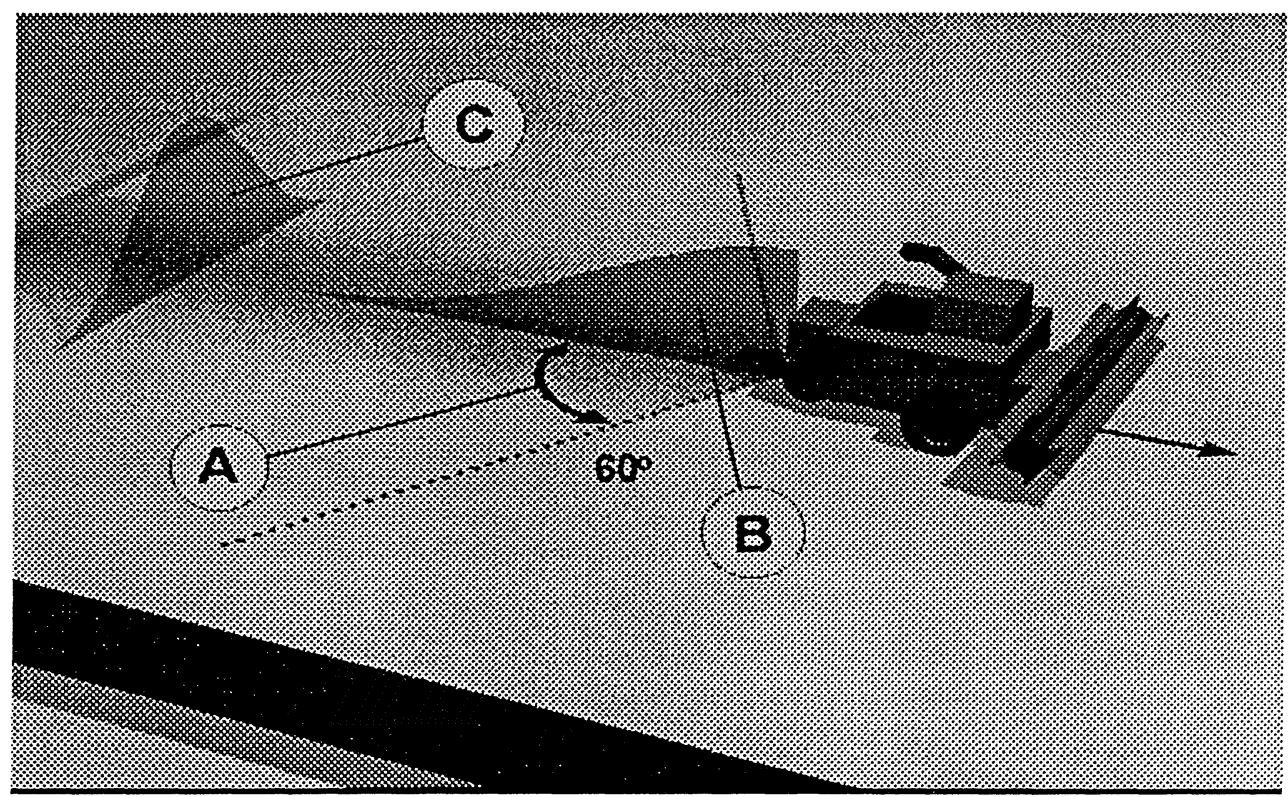

Figure 2. The seed spread mechanism for the combine harvester model. Direction of the thrown seeds is determined uniformly from -60 to +60 degrees (A), respective to the swath center line. The distance is proportional to a Cauchy distribution (B). The resulting distribution of seeds is unimodal and symmetric (C). 


\section{L ife Table Analysis}

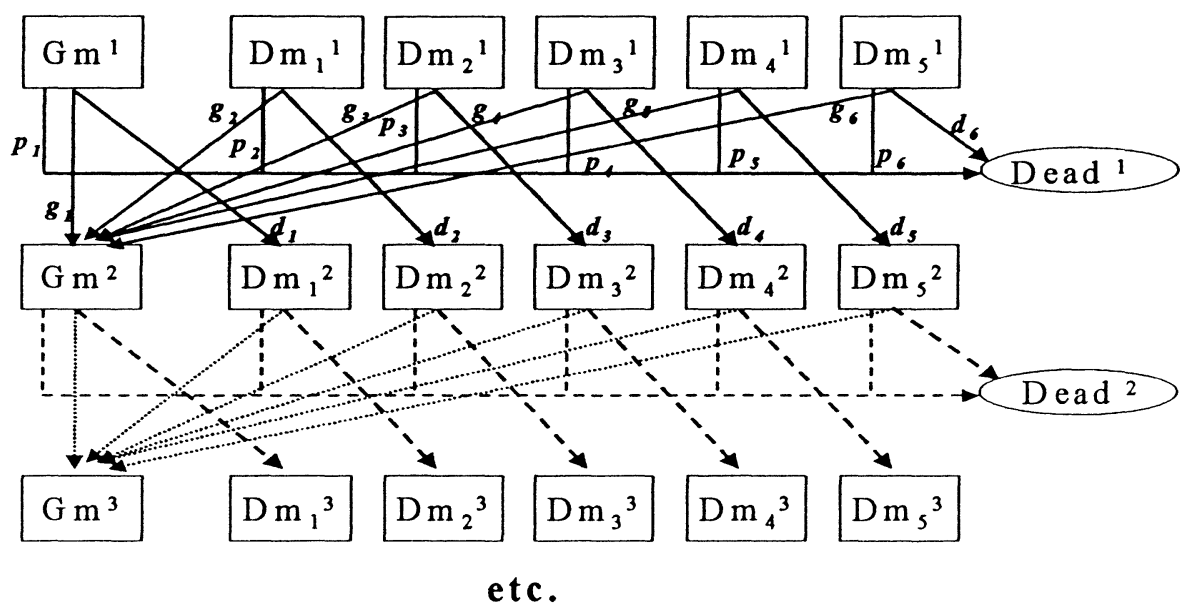

Figure 3. The life table distribution of wild oat seeds. For each cohort, seeds may be classified as germinated $(\mathrm{Gm})$, dormant $(\mathrm{Dm})$, or dead in the following season. This is based on the probabilities $g_{1}-g_{6}, d_{1}-d_{6}$, and $d_{1}-d_{6}$, respectively. Subscripts indicate cohort, while superscripts indicate year.

\section{Simulated Edge Infestation}

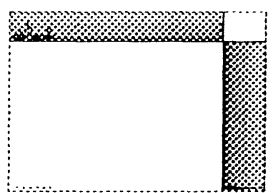

Year 1

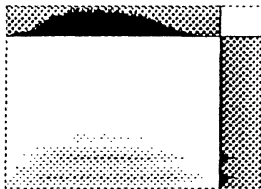

Year 5

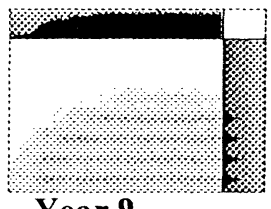

Year 9

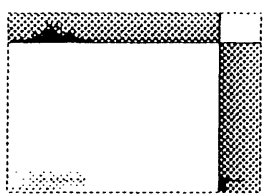

Year 2

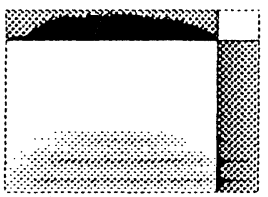

Year 6

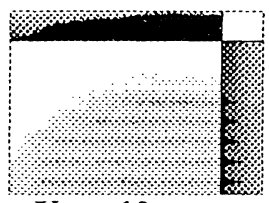

Year 10

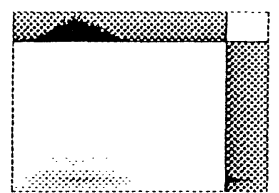

Year 3

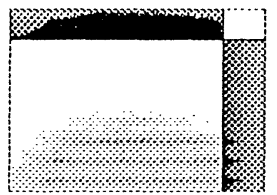

Year 7

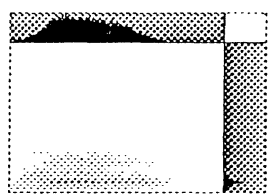

Year 4

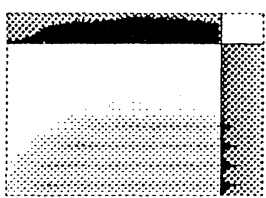

Year 8

Figure 4. Graphical summary for a 10-year simulation of an edge infestation. Shaded patches represent wild oat infestations where darker shades indicate higher plant densities. Profile plots representing the number of plants are given at the top and right of each respective graph. 


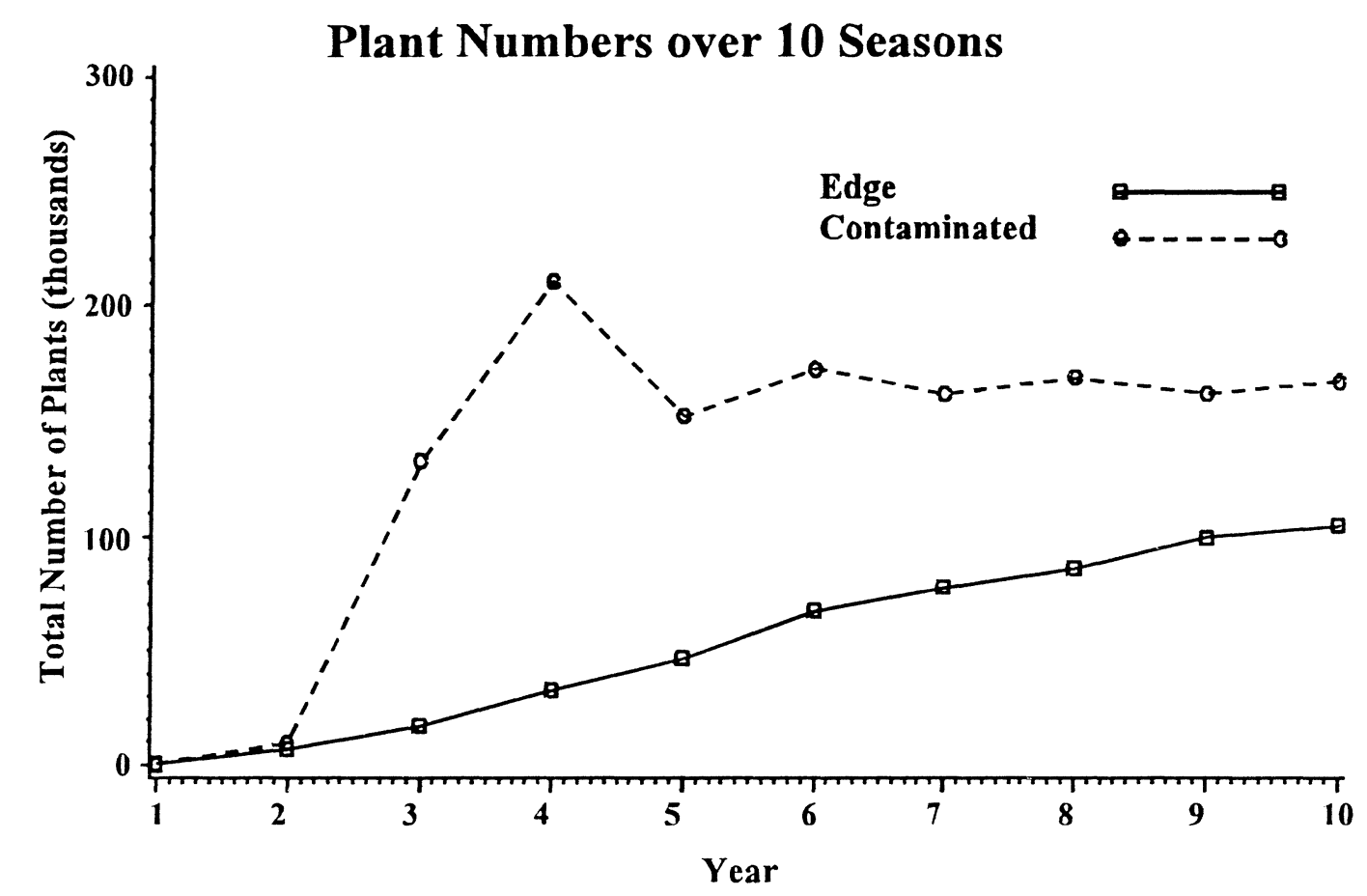

Figure 5. Total number of plants during two 10-year simulations of an edge infestation (solid line) and contaminated crop seed scenarios (dashed line).

\section{Plant Numbers over 10 Seasons}

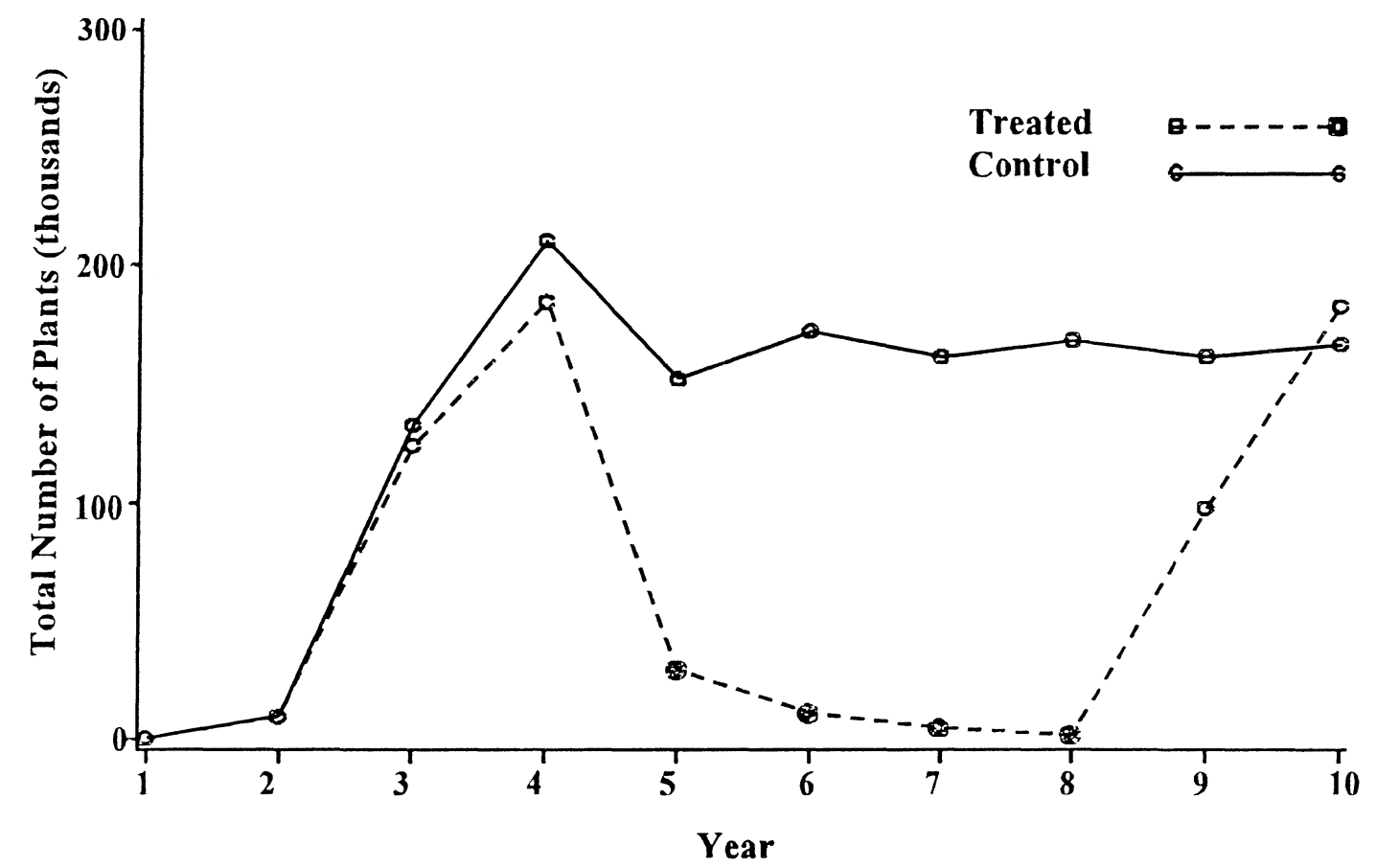

Figure 6. Total number of plants during two 10-year simulations of an untreated field (solid line) and a herbicide treated field (dashed line). 


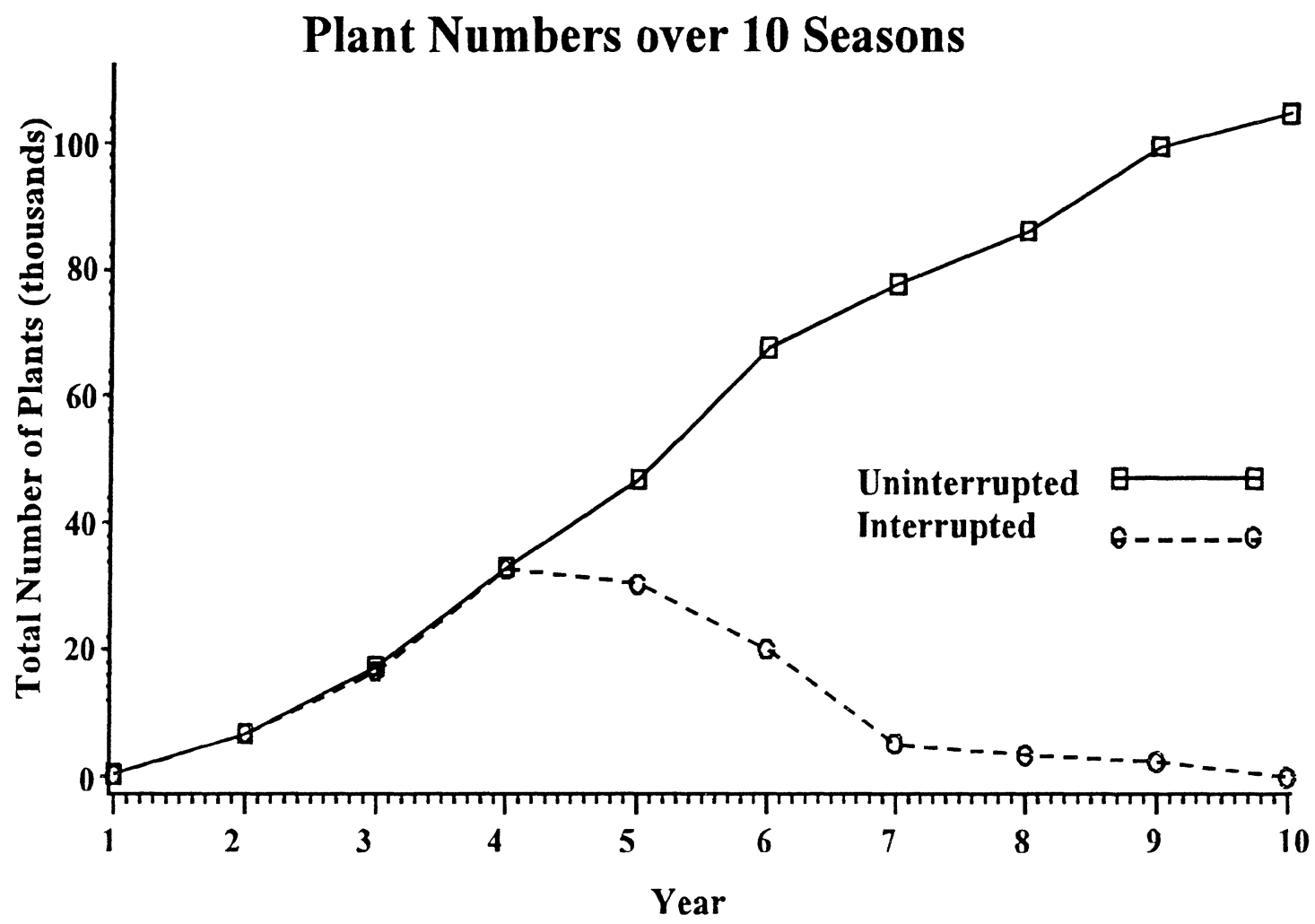

Figure 7. Total number of plants during two 10-year simulations with continuous (solid line) and interrupted (dashed line) wild oat seed production. 